\title{
Implementation and Assessment of a Curricular Module on the History and Philosophy of Reverse Engineering in Biological Systems
}

\section{Dr. Dominic M. Halsmer PE, Oral Roberts University}

Dr. Dominic M. Halsmer is former Dean of the College of Science and Engineering at Oral Roberts University, and currently serves as the Director of the ORU Center for Faith and Learning. He has been teaching engineering courses there for 20 years, and is a registered Professional Engineer in the State of Oklahoma. He received B.S. and M.S. Degrees in Aeronautical and Astronautical Engineering from Purdue University in 1985 and 1986, and a Ph.D. in Mechanical Engineering from UCLA in 1992. He is currently pursuing an M.A. in Biblical Literature from Oral Roberts University. His current research interests involve contributions from the field of engineering to the current science/theology discussion, reverse engineering of natural systems, and the preparation of scientists and engineers for missions work within technical communities.

\section{Hon. Peter Wesley Odom Mr., Oral Roberts University}

P. W. Odom is currently an undergraduate student of Engineering Physics at Oral Roberts University. His intentions are to begin graduate work in modern physics and engineering after graduation with the eventual goal of obtaining a Ph.D. and becoming a professor of engineering and physics related courses. Areas of particular interest include research in electromagnetism, optics and relativity.

\section{Jessica Fitzgerald, Oral Roberts University}

Jessica Fitzgerald is a Junior Engineering Physics major at Oral Roberts University. She currently works as a research assistant to Dr. Dominic Halsmer, Director of the Center for Faith and Learning at ORU. She is an honors student, and currently serves as the Resident Advisor on her floor.

\section{Mr. Taylor Gipson Tryon, Oral Roberts University}




\title{
Implementation and Assessment of a Curricular Module on the History and Philosophy of Reverse Engineering in Biological Systems
}

\begin{abstract}
With the current prominence of systems biology and the prevalent application of reverse engineering techniques to biological systems, there is wide recognition of the need, not only for proper methodology, but also for background information, which would serve to guide these activities, and help to place them in an appropriate context. The reverse engineering of biological systems has a long and distinguished history, from Galen and DaVinci, to William Harvey and E.O. Wilson. In addition, consideration of the moral and philosophical underpinnings and implications of such work provides biomedical engineering students with a useful arena in which to wrestle with questions regarding how their academic discipline integrates with their larger worldview.

Under the direction of faculty members from engineering, biology and philosophy, a multidisciplinary team of undergraduate honors students is developing a curricular module on the history and philosophy of reverse-engineering. In keeping with the mission of the institution, learning objectives and educational outcomes are carefully defined to assist with assessment of student learning. This module is currently being implemented among a group of engineering students in a course on the history of quantitative thought. Assessment activities are being conducted in an effort to determine if objectives and outcomes are being met. It is anticipated that both the students taking the course, and the students developing the curricular module, will significantly benefit from these experiences.

Current engineering graduates will live and work in an age where humanity is in danger of technologically outpacing its ability to wisely implement futuristic ideas. And yet, who better to assist in leading this complex society than problem solving engineers who have been educated in the history and wisdom of technological development. This is especially true in the fields of biomedical engineering and systems biology where strong leadership is needed to channel the vast expansion of new knowledge in a way that accomplishes the most good, and avoids the pitfalls resulting from limited human understanding. Combining historical and philosophical perspectives in systems biology allows students to view past technological achievements in a moral context, which should provide them with insights into current ethical dilemmas in biomedical engineering. It also provides students with a clearer understanding of reverse engineering techniques and the philosophical implications of the significant and repeated successes of such an approach to biological systems.
\end{abstract}




\section{The Role of Reverse Engineering in Engineering Education}

A recent article in ASEE Prism Magazine refers to a prominent astrophysical institute's attempts at "reconstructing and visualizing the universe's early days" as "the ultimate reverse engineering project." This reference to science as the reverse engineering of natural systems is consistent with the National Academy of Engineering's (NAE) recent announcement that one of their Grand Challenges for the twenty-first century is to "reverse engineer the human brain.", Many scientists and engineering educators are now beginning to recognize the value of the reverse engineering mindset, not only for unraveling the mysteries of nature, but also for teaching the intricacies of design in the engineering laboratory. The last two decades have seen a significant increase in the number of universities that have integrated this method into their teaching. ${ }^{3}$ Reverse engineering is simply taking an object apart and analyzing its "inner workings," in order to understand the secrets behind its operation. However, some researchers use a broader term, Disassemble/Analyze/Assemble (DAA), for these activities. ${ }^{4}$

A study comparing the results of such activities to the more traditional laboratory approach concludes that DAA activities have the potential to increase student motivation and promote transfer. ${ }^{5}$ Transfer refers to the ability to apply or adapt knowledge when seeking a novel solution to a problem. New courses are being developed that make use of reverse engineering projects to help students observe actual designs during "incremental concrete experiences," allowing them to reflect on the "big picture" of engineering. ${ }^{6}$ One such effort integrates the introduction to engineering course and the engineering graphics course around a reverse engineering project, making use of 3-D computer modeling and rapid prototyping of the disassembled parts for reengineering considerations. ${ }^{7}$ Another study compares eight different methods for teaching design to first-year students and concludes that a reverse engineering model is preferred. ${ }^{8}$

An attempt to increase student interest is made by creating a game whereby students are awarded achievement levels for gaining particular insights during reverse engineering activities. ${ }^{9}$ One engineering educator went so far as to report that reverse engineering has "proven to be the instructor's fire keg that lights the imaginations of the engineering students." 10 Another project attempts to "escape the tedium" of traditional instruction by charging students with the task of recreating an improved version of an existing mechanical artifact with the Lego Mindstorms ${ }^{\mathrm{TM}}$ kits. ${ }^{11}$ This focus on improving an existing design is also emphasized in a course where reverse engineering activities lend insight into "evolutionary product design," which also assists with

student retention. ${ }^{12}$ In another course, students are encouraged to dissect "a device with some kind of malfunction to study the reason behind the unit breakdown," and try to come up with conceptual ideas for improvement based on their studies. ${ }^{13}$ 


\section{Reverse Engineering and Design Recovery}

These kinds of activities demonstrate the value of reverse engineering for answering deeper questions than simply how a product works. Good questions range from how the components are designed, what materials are used, how the parts are assembled and how each component functions as part of the whole, to what criteria and constraints are met, what primary need is addressed, what engineering disciplines contributed, what limitations exist in the design and how the product might be misused. ${ }^{14}$ In this regard, some researchers make a distinction between reverse engineering (as artifact dissection for recovering its mechanisms of operation) and design recovery, which has "the goal of recovering the design processes that went into creating the artifact," emphasizing the later, rather than the former. They argue that design recovery considerations are the key to confronting students' common design misconceptions. ${ }^{15}$ While somewhat dependent on the particular field of study, other researchers have a slightly different definition for design recovery.

One helpful article, although dealing mainly with the reverse engineering of computer software, provides more detail on the concept of design recovery. Here, it is defined to be "a subset of reverse engineering in which domain knowledge, external information, and deduction or fuzzy reasoning are added to the observations of the subject system to identify meaningful higher level abstractions beyond those obtained directly by examining the system itself." ${ }^{\prime 16}$ In other words, the goal of design recovery is to work out, at a higher level of understanding, what a system or component was engineered to do, and (to some degree of confidence) why, rather than just examining its subcomponents and their interrelationships. This generally involves extracting design artifacts, by detecting design patterns for example, and synthesizing abstractions that are less dependent on implementation. It is these higher level abstractions that the authors of the current paper believe to be the key to fully reverse engineering complex natural systems. "Design recovery recreates design abstractions from a combination of code [system], existing design documentation (if available), personal experience, and general knowledge about problem and application domains...Design recovery must reproduce all of the information required for a person to fully understand what a program [system] does, how it does it, why it does it, and so forth." ${ }^{17}$ The development of a comprehensive design recovery framework for mechanical components ${ }^{18}$ appears to be a promising approach that addresses these questions.

\section{Reverse Engineering of Natural Systems in Engineering Education}

Reverse engineering activities can even be helpful in advancing engineering education, and relating science and engineering, in the P-12 classroom. Such activities are advocated since younger students do not know all the intentions of the original engineer and must infer them by observing and systematically evaluating the causal relationships that produce functionality. "This process is not trivial and can involve very similar scientific inquiry skills used to understand 
natural systems." ${ }^{19}$ Indeed, natural systems have become popular objects of reverse engineering activities at the university level also. Students learn the biomedical engineering design process by developing 3-D physical models of human anatomy based on medical imaging data using rapid prototyping and reverse engineering. ${ }^{20}$ Other modules have been developed to teach chemical engineering students how to apply engineering principles to living systems. These modules include reverse engineering of the human body, the beer making process, and the design of a microbial fuel cell. ${ }^{21}$

Other studies highlight the multidisciplinary aspect of this approach. 'The human body is an exquisite combination of interacting systems which can be analyzed using multidisciplinary engineering principles...Students are engaged in the scientific discovery process as they explore the engineering systems within the human body using exciting hands-on "reverse engineering" methods. ${ }^{22}$ Since students have a natural curiosity to learn how their own bodies work, such activities are thought to increase understanding and retention of new concepts, such as energy balances in the human body. ${ }^{23}$ Other researchers use modules on the reverse engineering of living systems and ecosystems to teach concepts that are vital for sustainability. ${ }^{24}$ Of course, the reverse engineering of the human brain (as per the NAE's Grand Challenges) is also being addressed by engineering educators and researchers. In an introductory digital signal processing course, students learn about "the process of collecting and analyzing electroencephalography data in a local neuroscience research laboratory." 25

\section{A Curricular Module on the History and Philosophy of Reverse Engineering in Biological Systems}

While the studies referred to previously are certainly interesting and valuable for engineering education, the authors seek to add background and context to these activities by proposing a curricular module on the history and philosophy of reverse engineering in biological systems. This module is not intended to be an extensive or exhaustive coverage of these topics, but rather will serve as a brief introduction to the subject. It is believed that this background information will further motivate and equip engineering students in the wise application of knowledge and stewardship principles when dealing with living systems. Not much has been found in the literature on the history and philosophy of reverse engineering in biological systems, although some preliminary discussions have been recently offered. ${ }^{26,27}$

The module is being developed by a multidisciplinary (engineering, biomedical engineering, philosophy) group of five undergraduate honors students under the guidance of faculty members from engineering, biology and philosophy. The students meet weekly to share research findings and discussion on the reverse engineering of natural systems. The module is being implemented and tested in an undergraduate honors course on the History of Quantitative Thought. This course is comprised of engineering majors, biology majors and some honors students in non- 
technical majors. The learning outcomes entail that, upon completion of this module, students will be able to:

1. Discuss the history of reverse engineering in biological systems

2. Discuss the philosophical issues and implications associated with the reverse engineering of biological systems

3. Discuss current techniques and applications in reverse engineering

4. Conduct an effective reverse engineering investigation

5. Work toward reconciliation of findings in biology with personal spirituality and worldview

6. Apply principles of stewardship and wisdom in dealing with ethical dilemmas in biology and biomedical engineering

This module contributes to the following educational objectives, which are among those that engineering graduates are expected to attain within a few years after graduation from this program:

1. Graduates will apply their technical knowledge to design and analyze systems and to solve ever-changing real world engineering problems

2. Graduates will engage in lifelong learning and professional development

3. Graduates will apply wisdom in the administration of stewardship principles and discipline, being committed to professional and ethical standards of responsibility

These learning outcomes will be accomplished (contributing to the realization of the educational objectives as well) through implementation of a curricular module consisting of the following elements:

1. Overview of the concept and techniques of reverse engineering

2. Legitimacy of applying reverse engineering principles to natural systems

3. Brief history of reverse engineering in biological systems

4. Overview of philosophical issues arising from reverse engineering in biological systems

5. Reverse engineering laboratory exercise \#1: Man-made object

6. Reverse engineering laboratory exercise \#2: Natural object (second-hand)

7. Testing and assessment activities

Several good books that discuss the concept of reverse engineering, its methods and techniques, are currently in use in academia and industry. ${ }^{28,29,30}$ The module will draw from these sources, as well as journal articles ${ }^{31,32}$ in providing an overview, with examples of both artificial objects and natural objects. A classic example of the reverse engineering of an artificial object is illustrated in the case of the Antikythera Mechanism. This 100-year-saga of the design recovery 
of what is thought to have been the first analog computer provides many insights into the potential and processes of reverse engineering. ${ }^{33}$ Several working models of the Antikythera Mechanism have now been developed based on the results of this reverse engineering project.

A fascinating example of the reverse engineering of a biological system is provided by a team of researchers who studied the mechanism by which E. coli bacteria withstand heat shock. ${ }^{34}$ Their study was reviewed by another team (consisting of an engineer and a pathologist) in a paper entitled, "Understanding Biology by Reverse Engineering the Control." The original team applied techniques such as "subtract and operate" in systematically eliminating both feedback and feedforward information pathways and observed the resulting performance. In assessing the overall achievement and results of the study, the reviewers concluded that "the mechanism used in Escherichia coli to combat heat shock is just what a well trained control engineer would design, given the signals and the functions available." 35

One can easily see that these kinds of conclusions naturally lead to interesting discussions about how such exquisite engineering can emerge by accident. Nevertheless, researchers continue to apply reverse engineering techniques to natural systems simply because it works. Biologist E. O. Wilson writes, "The surest way to grasp complexity in the brain, as in any other biological system, is to think of it as an engineering problem... Researchers in biomechanics have discovered time and again that organic structures evolved by natural selection conform to high levels of efficiency when judged by engineering criteria."36 This is reason enough to legitimize its application to natural systems, and especially in systems biology, which has been defined as "the quantitative analysis of networks of dynamically interacting biological components, with the goal of reverse engineering these networks to understand how they robustly achieve biological function." 37

Several sources provide a step by step method for conducting a reverse engineering investigation. Although the paper cited earlier by Wilson and Rosen, entitled "Systematic Reverse Engineering of Biological Systems," is primarily aimed at determining biological solutions for technological advancement, they provide the following helpful "Steps for Reverse Engineering Biological Systems.”

1. Identify and detail sub-function of interest

2. Identify candidate biological systems

3. Decompose architecture of biological system of interest

a. Decompose physical architecture

b. Decompose functional architecture

4. Identify state and function cycles

5. Develop behavioral model and truth table for functionality

6. Extract biological strategy in abstract form 
7. Idea generation (for engineering technologies to mimic this strategy)

An illustrative example of reverse engineering bird wings to assist in the development of morphing aircraft wing structures is also offered in the paper. ${ }^{38}$ The structure of bird wings have recently received attention as elegant optimal solutions to multiple ${ }^{39}$ and particularly difficult ${ }^{40}$ engineering problems. The next section contains examples of some material that will provide a historical perspective of reverse engineering. This material also provides a good lead-in to some of the important philosophical issues that arise.

\section{Historical Examples in Galen and William Harvey}

Aelius Galenus, or otherwise known as Galen of Pergamon, was a well known Roman scientist and physician around $170 \mathrm{AD}$. His anatomical discoveries about the physiology of the body were studied for hundreds of years after his death, even into the nineteenth century. As a student of Hippocrates, Galen was constantly focused on learning more about the world around him, especially when it concerned the workings of the body. Eventually finding himself at the prestigious medical school in Alexandria, he began to sharpen his understanding about the theories of the body of the time. He continued this education by taking a position as a surgeon to the gladiators, where he learned much about the treatment of injuries, maintenance of hygiene, and living anatomy.

It wasn't until $162 \mathrm{AD}$ that Galen left for Rome to establish himself as a prominent physician. It was at this time, while he was the acting physician under Marcus Aurelius that Galen began to contribute to scientific understanding. Galen was most noted for his theories on the circulatory system. Since human dissection was banned in Rome during Galen's time, he had to settle on dissecting pigs and other animals. It was through this that Galen learned much about the circulation of blood through the body and the various parts that perform those functions.

However, dissections were not the only means by which Galen was able to make these discoveries. During this time, there were two main schools of thought relating to the proper way to do science. The first were the Empiricists, who believed that the only way to go about finding scientific truth was through direct observation of physical phenomena. The second were the Rationalists, those who held the belief that study of already established teachings through philosophical reasoning was the correct method. Galen, rather than choosing one side or the other, thought it best to combine the two schools of thought. This became known as being a Methodist. Galen understood the need for direct observation in scientific discovery (empiricism), but he did not discount the importance of philosophical reasoning in the pursuit of scientific truth (rationalism). 
Galen was very philosophical and was a firm believer in involving philosophy and purposeful thinking in scientific endeavors. In his work entitled That the Best Physician is also a Philosopher, Galen emphasized the fact that science should be considered a cross disciplinary art, making use of observation as well as philosophical thought. Galen also held the belief that "Everything in nature has a purpose, and that nature uses a single object for more than one purpose whenever possible." This principle continues to evoke wonder, even today, as evinced by a recent article where a biological engineering researcher at MIT writes, "Nature, it appears, copies and pastes design elements for motors with similar roles and physical constraints. Despite different tracks and overall purposes for motility, all of the designs of common biological machines have been optimized." 41 This perceived economy of nature was what drove Galen to consider the way by which the blood received oxygen. He deduced that the heart was not only vital in driving the blood through the body, but also driving it to be resupplied with vital oxygen. Although some of his thoughts were incorrect, he established the main concept of the circulatory system through the use of direct observation and purposeful reasoning. ${ }^{42}$

Galen's views on the anatomy of the circulatory system continued to be the standard for hundreds of years after his time. The view remained generally the same until a physician by the name of William Harvey challenged the teaching with his own new theory in the mid 1600's. William Harvey was the son of Thomas Harvey, a wealthy politician and governor of Folkestone, England. Being born into a privileged family gave young Harvey the chance of furthering his education and pursuing higher degrees. After graduating from Caius College in 1597, Harvey travelled to the medical college at Padua where he would find his calling as a physician. Harvey was an excellent student, familiarizing himself with all the theories and knowledge of the time. It was once said about him that he "conducted himself so wonderfully well in the examination and had shown such skill, memory and learning that he had far surpassed even the great hopes which his examiners had formed of him."

After graduating from Padua in 1602, the now 24 year old Harvey travelled back to London to practice medicine. After some time, his skill showed through and he was eventually appointed to physician of King James I in the year 1612. It was in this station that Harvey began to start his research and further his understanding about the anatomy of the human body. Harvey spent these years focused upon the circulatory system of the body. He was fascinated with the process of blood circulation, and was continually searching for the truth behind the process. As "physician extraordinary" to James I, Harvey had some access to cadavers by which to conduct his research. This access to the human body proved invaluable in Harvey's research, however he began to see things that did not match up to the commonly held teachings of the time.

During the 1600's the view of the circulatory system was that of a body full of veins which could pump blood both to and from the heart simultaneously. Harvey, however, noticed a problem with this theory. He discovered that there was a network of valves placed throughout the circulatory 
system within the veins. These valves were shown to resist the flow of blood when closed. Also, they were shown to work in only one direction. Other scientists had noticed this anomaly as well, but had discounted it. In 1628, however, Harvey went against the commonly held view by publishing his work De Motu Cordis, in which he outlined his findings. Harvey postulated that there were actually two veinous systems involved in the circulatory system: veins and arteries. These were both one-way systems, with arteries carrying blood away from the heart and veins carrying the deoxygenated blood back to it.

This discovery was based upon his thoughts on the quantity of valves in the circulatory system. Harvey said, "I was invited to imagine that so provident a cause as nature had not placed so many valves without design: and no design seemed more probable than that... it [the blood] should be sent through arteries and return through veins, whose valves did not oppose its course that way." Harvey, rather than merely looking at empirical evidence, chose to deduce that nature would design a system to work utilizing all of the components efficiently. Hence, Harvey's theory on circulation would provide the "best" explanation of why there were so many valves present in the circulatory system. This theory was rejected by Harvey's peers, and it wasn't until much later that his work was fully appreciated and proven to be true. However, it is important to understand that his discovery of this system was brought about through a combination of empirical findings and rational reasoning with a reverse engineering mindset. Harvey went about science by considering natural systems as designed entities with purpose and intent in their

function. ${ }^{43,44}$ Indeed, a recent article suggests that methodological naturalism may be too restrictive for achieving the most insight during reverse engineering investigations. ${ }^{45}$

\section{Connections between Science/Engineering and Philosophy}

Other researchers throughout the history of science and engineering have made similar connections to philosophy (consisting of the sub-disciplines of epistemology, logic, ethics, metaphysics, and aesthetics). After detailed dissections and analyses of the human body, Leonardo DaVinci is credited with the following statement, "The human foot is a masterpiece of engineering, and a work of art." A recent book on reverse engineering claims, "The human body is a beautiful piece of engineering work in nature. Reverse engineering is the most effective way to reinvent the component parts of this engineering marvel due to lack of the original design data."46

A recent article in Mechanical Engineering provides the following explanation, "Through biological evolution, Nature has conducted a 3.8 billion-year research and development program, and we find ourselves preparing to make commercial use of its discoveries." 47 This is a very interesting state of affairs, rife with metaphysical implications. In a new paper on the origin of life for the Royal Society journal Interface, cosmologist Paul Davies writes, "To a physicist or chemist, life seems like 'magic matter.' It behaves in extraordinary ways that are unmatched in 
any other complex physical or chemical system. Such lifelike properties include autonomy, adaptability and goal-oriented behavior - the ability to harness chemical reactions to enact a preprogrammed agenda, rather than being a slave to those reactions." ${ }^{48}$ This reference to "magic matter" is reminiscent of Eden Philpotts famous quote, "The universe is full of magical things, patiently waiting for our wits to sharpen." ${ }^{, 49}$ It appears that even though he wrote this in 1918, the universe is still patiently waiting. Even the title of militant atheist Richard Dawkins' latest book refers to the "Magic of Reality." sufficiently advanced technology is indistinguishable from magic." ${ }^{.51}$ But from where does such advanced technology come? Could it actually be obtained without intentionality, that is, by accident?

Biologist Francois Jacob pictured evolution as a tinkerer, as opposed to an engineer ${ }^{52}$ but how is only a tinkerer able to produce "stunningly well-engineered" ${ }^{53}$ systems? To be fair, not all scientists agree that the human body is so well-engineered. Biologist John Avise ${ }^{54}$ and science writer Philip Ball ${ }^{55}$ argue that such "shoddy" workmanship, as seen, for example, in diseasecausing genetic malfunctioning, is not worthy of attributing to any form of intelligence. Even so, explanations for the "dark side" of the human condition that are consistent with new findings from the fledgling field of epigenetics have recently been offered. ${ }^{56}$

A more recent article by biologist Uri Alon takes up Jacob's discussion of tinkerer vs. engineer. ${ }^{57}$ In this article, Alon aims to compare evolution and evolutionary processes to that of a "tinkerer," instead of an engineer. He says that unlike an engineer, tinkerers do not plan out what they are going to do, nor do they use any type of process to come to a certain solution. Instead, they use a process of guess and check, and try different things until they find something that works-a process of elimination. Though Alon makes this claim, that evolution is much like a "tinkerer," he does state that the "solutions found by evolution have much in common with good engineering design." He elaborates on three examples of these similarities between engineered systems and biological systems: modularity, robustness, and the use of recurring circuit elements.

The first, modularity, Alon defines as "a set of nodes [in a system] that have strong interactions and a common function." In order for a set of nodes to be identified as a module, there must be input and output nodes, as well as internal nodes that do not have much effect on the nodes outside the module. Alon explains how networks with modularity, both in engineering and biological networks, make a system more adaptable to many different situations, because of the modules' unique attributes. Though non-modular devices and networks exist in both engineered and natural systems, modular systems have the advantage because each component is not frozen by its inability to adapt; in modular networks, when new conditions arise, each can be configured and optimized to meet the new requirements - without the need for the whole system to change collectively. 
The second similarity between biological networks and engineered systems is the need for robustness. Alon points out that the systems that survive the most in nature have the ability to work under several different conditions, in several different environments. This need for robustness, Alon claims, "imposes severe constraints on its design," thus narrowing the vast range of possible designs on paper to only a few that are adaptable enough to survive under the several demands that are placed on the system due to changing conditions.

The third, and final parallel found in both biological networks and engineered systems is the existence of recurring circuit elements. Both types of systems use repeated elements in a design to help the system carry out its function. These recurrences in biology are known as "network motifs," and are found across several diverse systems; for example, similar network motifs are found in both the E. coli bacteria and the transcription network of yeast. Alon is careful to point out that just because network motifs exist; it does not mean that these similar circuits are duplicated one from another. It simply means that evolution, as a "tinkerer" seems to converge on the same network motifs time and again because these are the systems that have been proven to be the most effective for a wide range of biological systems. Once a motif has been defined, Alon claims, and a dictionary of sorts is completed, it will aid researchers in identifying different network motifs in each new network they come across, enabling a quicker identification and classification process.

Each of these comparisons between biological networks and engineered systems may help humans understand and model natural systems. It is a huge task to undertake, to understand completely the vast range of cell-wide networks. The similarities between evolution as "tinkerer" and the engineer also raise the challenge, Alon states, of "understanding the laws of nature that unite evolved and designed systems."

\section{Reverse Engineering Laboratory Experience}

A key aspect of the module is the reverse engineering laboratory experience. The students first conduct a reverse engineering investigation into an artificial object, such as a simple electric motor or an aquarium pump. Dissection is conducted and reverse engineering techniques and methodology is followed to determine the nature of the device and the details of its design. Necessary tools and instruction are provided to allow the students to safely accomplish this investigation. The students are required to write a report that communicates the details of their investigation and the conclusions that were drawn.

The students next conduct a reverse engineering investigation into a natural motor or pump that is regularly found in biological systems at the molecular level. Unfortunately, since not all the students in this class (History of Quantitative Thought) are biology majors, and hence lack the skill and equipment to conduct such an investigation first-hand, this is a "second-hand" or "virtual" reverse engineering investigation. In other words, students will gather digital 
information on the subject system reported by those who have conducted such investigations. Although perhaps not as valuable as a first-hand experience, students learn how to take advantage of the wealth of scientific and engineering information that is currently available on biological systems. Similar to the reverse engineering experience with the artificial object, students collect enough information to complete their investigation of the natural system, after which, they also write a report. In this report, they are asked to compare and contrast the workings of the artificial and natural systems, and draw conclusions with regard to the origins of each system. They are also asked to discuss any impact the module might have had on personal worldview and/or spirituality.

\section{Assessment of the Module and Conclusions}

Laboratory reports are graded and returned to the students in a timely fashion. Midterm and final examinations are conducted that contain questions relating to material from the module on reverse engineering. Grades from the laboratory reports and examinations are used to assess the achievement of the learning outcomes. Pre- and post-module test/surveys are also conducted to help with assessment of learning outcomes. Student comments regarding the effectiveness (or lack thereof) of the module are also requested, both at the end of the module and at the end of the course.

A shorter, preliminary version of this module has been conducted with small groups of undergraduate engineering and honors students over the past few years. An overwhelming amount of positive feedback, both anecdotally and from student opinion surveys, has encouraged further development of the more comprehensive module, which will be implemented by the end of January of 2013, with more complete assessment data available for the final draft of this paper. Currently, assessment of the preliminary version, based on a five point Likert scale survey, indicates that participants are assisted in reconciling problems in science and faith (4.2), realize a greater sense of understanding and personal purpose (4.6), and are assisted in their ability to communicate with others on issues in science and faith $(5.0) .{ }^{58}$ In other words, all the surveyed participants strongly agreed that they had been assisted in communicating with others on issues in science and faith. The assessment instrument is currently being rewritten to cover the more complete set of learning outcomes and revised terminology associated with the comprehensive module. It is anticipated that assessment results from students taking the comprehensive module will be similar to those who have experienced the preliminary version.

Assessment results for the comprehensive module on the history and philosophy of reverse engineering in biology are very encouraging. Based on a five point Likert scale, students generally agreed that participation in the module helped them understand the history of reverse engineering in biology (3.8), helped them understand the philosophy of reverse engineering in biology (4.4), helped them understand current techniques and applications in reverse engineering 
(4.2), taught them how to conduct an effective reverse engineering project (4.1), helped them reconcile modern biology with personal spirituality and worldview (4.3), and helped them apply principles of stewardship and wisdom in dealing with ethical dilemmas in biology (3.4). The relatively low score on the last item indicated that perhaps more time should be devoted to stewardship and ethics in the future. Ninety-two percent of respondents either agreed or strongly agreed that the module both helped them understand the philosophy of reverse engineering in biology, and helped them understand current techniques and applications in reverse engineering. Multiple respondents indicated their desire to have more time devoted to this subject. One respondent thought students should be "required to engineer/design/construct a device" rather than simply conduct a dissection. Another respondent appreciated being "asked thoughtprovoking questions in regard to the implications of our findings." Although the sample size is relatively small (class of 14 with 2 absent on assessment day: $\mathrm{N}=12$ ), the positive results and feedback are motivating and informing the continuing development of this module for implementation in other courses at Oral Roberts University such as Introduction to Engineering and Biomedical Engineering Survey.

\section{Bibliography}

1. Buki, A. \& Grose, T. K., Dream Factory: University Engineers Are Often the Hidden Stars Behind OnScreen Excitement, Prism, ASEE, Washington, D.C., p. 33, September 2012.

2. Introduction to the Grand Challenges for Engineering, engineeringchallenges.org, 1 Jan. 2013, http://www.engineeringchallenges.org/cms/8996/9221.aspx

3. Wu, C., Some Disassembly Required, Prism, ASEE, Washington, D.C., pp. 56-59, October 2008.

4. Ogot, M., \& Kremer, G., Developing a Framework for Disassemble/Assemble/Analyze (DAA) Activities in Engineering Education. Proceedings of the ASEE Annual Conference \& Exposition, 2006.

5. Dalrymple, O. O., Sears, D. A. \& Evangelou, D., The Motivational and Transfer Potential of Disassemble/Analyze/Assemble Activities, Journal of Engineering Education, 100(4), pp. 741-759, October, 2011.

6. Wood, K. L., Jensen, D., Bezdek, J. \& Otto, K. N., Reverse Engineering and Redesign: Courses to Incrementally and Systematically Teach Design, Journal of Engineering Education, 90(3), pp. 363-374, July, 2001.

7. Barr, R. E., Schmidt, P. S., Krueger, T. J. \& Twu, C. Y., An Introduction to Engineering through an Integrated Reverse Engineering and Design Graphics Project, Journal of Engineering Education, 89(4), pp. 413-418, July, 2000.

8. Burton, J. D. \& White, D. M, Selecting a Model for Freshmen Engineering Design, Journal of Engineering Education, 88(3), pp. 327-332, July, 1999.

9. Foster, J. A., Sheridan, P. K., Irish, R. \& Frost, G. S., Gamification as a Strategy for Promoting Deeper Investigation in a Reverse Engineering Activity, Proceedings of the ASEE Annual Conference, 2012.

10. Hess, H. L., Solid Modeling and Reverse Engineering: The Stimulus for Teaching Manufacturing, Proceedings of the ASEE Annual Conference, 2002. 
11. Campbell, M. I., Teaching Machine Design through Product Emulation, Proceedings of the ASEE Annual Conference, 2002.

12. Orono, P. O. \& Ekwaro-Osire, S., Evolutionary Design Paradigm as a Retention Tool, Proceedings of the ASEE Annual Conference, 2005.

13. Rad, H., Reverse Engineering as a Learning Tool in the Design Process, Proceedings of the ASEE Annual Conference, 2012.

14. Kellogg, R. S. \& Jenison, R., Utilizing Reverse Engineering to Explore the Design Process, Proceedings of the ASEE Annual Conference, 1997.

15. McCracken, W. M. \& Newstetter, W., Reverse Engineering or Design Recovery: Two Approaches to Uncovering Designing, Proceedings of the ASEE Annual Conference, 2000.

16. Chikofsky, E.J. \& Cross, J.H. II, Reverse Engineering and Design Recovery: A Taxonomy, IEEE Software, p. 15, January 1990.

17. Biggerstaff, T.J., Design Recovery for Maintenance and Reuse, Computer, pp. 36-49, July, 1989.

18. Urbanic, R.J. and El Maraghy, W.H., A Design Recovery Framework for Mechanical Components, Journal of Engineering Design 20(2), pp. 195-215, April, 2009.

19. Brophy, S., Klein, S., Portsmore, M. \& Rogers, C., Advancing Engineering Education in P-12 Classrooms, Journal of Engineering Education, 97(3), pp. 369-387, July, 2008.

20. Sirinterlikci, A., Teaching Biomedical Engineering Design Process and Development Tools to Manufacturing Students, Proceedings of the ASEE Annual Conference, 2012.

21. Hollar, K., Farrell, S., Hecht, G. B. \& Mosto, P.B., Integrating Biology and Chemical Engineering at the Freshman and Sophomore Levels, Proceedings of the ASEE Annual Conference, 2003.

22. Farrell, S., Kadlowec, J., Marchese, A., Schmalzel, J. \& Mandayam, S., Hand-on Experiments: Engineering and the Human Body, Proceedings of the ASEE Annual Conference, 2004.

23. Farrell, S., Savelski, M. J. \& Hesketh, R., A Hands-on Introduction to Energy Balances on the Human Body, Proceedings of the ASEE Annual Conference, 2003.

24. Jahan, K., The Aquarium Project: Teaching Engineering Principles and Sustainability, Proceedings of the ASEE Annual Conference, 2007.

25. Huettel, L. G., Connecting Theory and Practice: Laboratory-based Explorations of the NAE Grand Challenges, Proceedings of the ASEE Annual Conference, 2011.

26. Halsmer, D., Halsmer, N., Johnson, R., and Wanjiku, J., The Applicability of Engineering Design Principles in the Formulation of a Coherent Cosmology and Worldview, Proceedings of the ASEE Annual Conference, 2008.

27. Halsmer, D., Todd, T. \& Roman, N., Integrating the Concept of Affordance into Function-based Reverse Engineering with Application to Complex Natural Systems, Proceedings of the ASEE Annual Conference, 2009.

28. Otto, K. \& Wood, K., Product Design: Techniques in Reverse Engineering, Prentice-Hall, Englewood Cliffs, NJ, 2000.

29. Wang, W., Reverse Engineering: Technology of Reinvention, CRC Press, Boca Raton, FL, 2011.

30. Sweigers, G, Lehn, J. \& Benyus, J., Bioinspiration and Biomimicry in Chemistry: Reverse-Engineering Nature, Hoboken, NJ, Wiley, 2012.

31. Csete, M. E. \& Doyle, J. C., Reverse Engineering of Biological Complexity, Science 295(5560), pp. 16641670, March, 2002.

32. Wilson, J. O. \& Rosen, D., Systematic Reverse Engineering of Biological Systems, Proceedings of the ASME International Design Engineering Technical Conferences, September, 2007.

33. Marchant, J., Decoding the Heavens, Da Capo Press, Cambridge, MA, 2009.

34. El-Samad, H., Kurata, H., Doyle, J. C., Gross, C. A. \& Khammash, M., Surviving Heat Shock: Control Strategies for Robustness and Performance, Proceedings of the National Academy of Sciences 102(8), pp. 2736-2741, February, 2005. 
35. Tomlin, C. J. \& Axelrod, J. D., Understanding Biology by Reverse Engineering the Control, Proceedings of the National Academy of Sciences 102(12), pp. 4219-4220, March, 2005.

36. Wilson, E.O., Consilience: The Unity of Knowledge, Knopf Publishing Group: Westminster, MD, p. 112, 1999.

37. IEEE Transactions on Automatic Control and IEEE Transactions on Circuits and Systems, p. 4, January, 2008.

38. Wilson, J. O. \& Rosen, D., Systematic Reverse Engineering of Biological Systems, Proceedings of the ASME International Design Engineering Technical Conferences, September, pp. 4-8, 2007.

39. Burgess, S. C., Multi-functioning and Multi-optimisation in Feathers, International Journal of Design and Nature 1(1), pp. 1-10, 2007.

40. Forsching, H. \& Hennings, H., Aeroelastic Mysteries in Avian Flight, CEAS Aeronautical Journal 3(2-4), pp.135-143, December, 2012.

41. Lang, M., Lighting Up the Mechanome, The Bridge: Linking Engineering and Society, National Academy of Engineering, p. 13, Winter, 2007.

42. Bos, F. L. Genetic Regulation of Angiogenesis and Lymphangiogenesis: Visualization and Characterization of the Developing Embryonic Vasculation. Self-published, 2011.

43. Brecher, G. A. "History of Venous Research." IEEE Transactions on Biomedical Engineering BME-16(4), pp. 236-247, 1969.

44. McMullen, E. T., William Harvey and the Use of Purpose in the Scientific Revolution: Cosmos by Chance or Universe by Design? Lanham, MD: University of America, 1998.

45. Halsmer, D. \& Fitzgerald, J., Metaphysical Considerations Enhance Reverse Engineering Studies," ASA Annual Meeting, North Central College, July 29 - August 1, 2011.

46. Wang, W., Reverse Engineering: Technology of Reinvention, CRC Press, Boca Raton, FL, p. 6, 2011.

47. Bhushan, B., Nature's Nanotechnology, Mechanical Engineering: The Magazine of ASME 134(12), p. 30, December, 2012.

48. Walker, S. I. \& Davies, P. C. W., The Algorithmic Origins of Life, Interface, (in press), December, 2012.

49. Philpotts, E., A Shadow Passes, Cecil Palmer and Hayward, 1918.

50. Dawkins, R. \& McKean, D., The Magic of Reality: How We Know What's Really True, Free Press, New York, 2012.

51. Clarke, A. C., Profiles of the Future, Macmillan: New York, p. 39, 1973.

52. Jacob, F., Evolution and Tinkering, Science 196 (4295), pp. 1161-1166, June, 1977.

53. Beckerman, M., Molecular and Cellular Signaling, Springer, New York, pp. vii-viii, 2005.

54. Avise, J. C., Inside the Human Genome: A Case for Non-Intelligent Design, Oxford University Press, Oxford, 2010.

55. Ball, P., What a Shoddy Piece of Work is Man, Nature News Online, May 3, 2010.

56. Halsmer, D. \& McDonough, S., Affordance-based Reverse Engineering of Natural Systems with Possible Corruption, Proceedings of the Christian Engineering Education Conference, Trinity Western University, June 29 - July 1, 2011.

57. Alon, U., Biological Networks: The Tinkerer as an Engineer, Science, 301, pp. 1866-1867, September, 2003.

58. Halsmer, D. \& Beck, J., Encouraging Spiritual Vitality through Multidisciplinary Discussions on the Role of Engineering in Reconciling Science and Faith Issues, presented at the Spirituality and Honors Education Symposium, Indiana Wesleyan University, May 29-31, 2012. 